SCHOLARS: Journal of Arts \& Humanities

Volume 3, No. 1, February 2021, pp. 103-112

[Peer-Reviewed, Open Access, Indexed in NepJOL]

Print ISSN: 2773-7829; e-ISSN: 2773-7837

DOI: https://doi.org/10.3126/sjah.v3i1.35379
Central Department of English

Tribhuvan University

Kirtipur, Kathmandu, Nepal

Theoretical/Critical Essay Article

\title{
Super-Cripple Sights: Disable Heroes in Raymond Carver's Cathedral and Sophocles' Oedipus Rex
}

\author{
Dipak Lungeli \\ Department of English \\ Mahendra Ratna Multiple Campus, Ilam, Nepal
}

Corresponding Author: Dipak Lungeli, Email: anon.kapid@gmail.com

Copyright $2021 @$ Author/s and the Publisher

\begin{abstract}
Robert and Tiresias, disable protagonists respectively of Raymond Carver's Cathedral and Sophocles' Oedipus Rex with their super cripple qualities challenge the imperatives of ableist ideals. Protagonists' blindness leads them to insight whereas their counter characters' sight leads them to darkness. Such a role reversal leads to a questioning of dichotomies and establishes an alternative view to the definition of blindness and insight. To support this claim, I use Lennard J. Davis' concept of disable bodies in literature, Rod Michalko's notion of fictional explorations of disability, and Nickianne Moody's model of disability informed criticism backed up by Judith Butler's notion of body politics, Rosemarie Thompson's idea of extraordinary bodies, and different critical readings on body. This framework of interpretation validates disable bodies as cultural construction. It also regards literatureas apt venue to challenge culturally assigned definition of ability and disability in favor of new body possibilities. The theoretical framework thus discovers Carver and Sophocles redrawing the concept of ablebodiedness and deeply rooted cultural hierarchies like able/disable, sight/blind, sight/insight, body/mind, visible/invisible, and inside/outside in their literary texts.

Keywords: Ableism, blindness, disability, insight, normalcy, sight, super-cripple body
\end{abstract}

\section{Introduction}

Is disability a mere difference? Are insight, truth and wisdom akin to normal physical eyes or to something else beyond?A YouTube video featuring the performance of Ramesh Prasain, a blind in the grand finale of 'Public Speaker Nepal', a nationwide speech competition, answers these questions. In his speech, Mr. Prasain spontaneously explores ideas on 'national sovereignty and foreign intervention' the topic assigned to him (Prasain 0:35-4:40). He astounds the juries and the audience with his super-crippling presentation. Denied of physical eyesight, Mr. Prasainproves with his cognitive eyethatperception of knowledge and insight are beyond physical eyes. He bags the title but on top of that he blurs the stereotypical borderland of sight and blindness. The reference of Prasain's performance is to posit thatRobert and Tiresias respective disable heroes of Raymond Carver's Cathedral and Sophocles' Oedipus Rex with their super- 
cripple ability challenge ableist ideals, transgress their metacritical traits, defy normative ideology, and establish an alternative view to the definition of blindness and insight.

\section{What Is Common in Cathedral and Oedipus Rex}

The critical assessments to the portrayal of Robert's blindness in Raymond Carver's Cathedral comprise divergent evaluations form different theoretical perspectives. Jorgen Bruhn associates the idea of Carver's blindness with problem of mediation and thus for him the subject of Cathedral is "not only obvious opposition between blindness and insight, but the inherent problems of mediation, including a deeprooted vision of a non-mediated presence" (63). But the critic Arthur Brown links the very mediation of Robert with the characteristics of humanist postmodernism. For him "the blind man's touching the face of the narrator's wife" as reading and writing and his contour drawing indicate "humanist postmodernism" (134). Unlike Bruhn and Brown, Polly Rose Peterson situates the locus of blindness in narrator's psyche of hatred that is demonstrated in his use of specific determiner to refer to his detachment with Robert. Peterson observes how the narrator's use of possessive determiner conveys "the story's central message on blindness" (167). For him, narrator's use of 'of' to refer to his wife and demonstrative determiner 'this' to indicate Robert simultaneously creates psychological closeness to the former and distance to the later. Robert C. Clark, on the other hand reads Robert's blindness from impressionistic view and narrator's perception of Robert as stance of minimalism. For Clark, despite his blindness, Robert perceives the world through his sensory capabilities, "an action common in impressionistic works" but the narrator like minimalist characters is "unable to articulate the significance of the events he describes" (104). Also, narrator's ironical situation of not being able to express the cause behind his resentment to Robert's blindness surprises Clark. However, Clark's view of narrator's minimalism for Taylor Johnston is a negation to postmodern culture.

Johnston finds the narrator in his minimality becoming persistently uncomfortable with the blindness of Robert which is metaphor of consumer culture. He defines the story as "allegory of the utopian possibility of experience removed from commodification in which blindness becomes a figure for the evacuation of consumer culture" (13). Johnston's view on narrator's minimalism for Chris J. Bullock is inferiority complex of his sight against overpowering blindness of Robert. From psychoanalytical perspective Bullock judges masculine rivalry between the narrator and Robert who are engaged in the drawing of cathedral. For Bullock, "the narrator's fear of blindness, then, suggests that control through vision is an important part of the functioning of the masculine ego" (346). Also, Bullock's psychoanalytical concern is on the denying nature of the narrator who distances himself so much from Robert.

The critical interventions on blindness of Tiresias, on the other hand, reveal two perspectives. First, the blindness that influences classical Greek time and its literary productions including Oedipus Rex is interpreted as merely physical one. Reading sight and blindness as represented in classical Greek literature and myths from medical lens Martha L. Rose finds "the story of blind people in the ancient Greek world is neither glorious nor dismal and that blind people were far from exceptional" (79). She is critical about modern way of looking at disability issues on ancient texts. Rather, for her the very cause of blindness in classical Greek in fact might have been the physical such as hereditary cataract and glaucoma and lack of nutrition (vitamin A) which were beyond 
their diagnostic knowledge as of modern time (83-87). Rose's refutation is against fate and punishment based view of blindness as forwarded by the critics. The justification of her claim is that "There is not enough relevant information to make similar conclusions about ancient Greek society" and thus, "what gets exaggerated in Greek myth-and present-day misunderstanding-as a superhuman gift" as seen in Tiresias and Oedipus is "fallacious" (79-88). Rose posits against fatalistic interpretation of blindness as transcendental domain of knowledge beyond human ability.

The second perspective on Tiresias' blindness is associated with curse and divine gifts. Conversely to Martha L. Rose's claim, Steven Lattimore interprets Tiresias as "the prophet of Apollo-who sees the same things as the god" (105). Lattimore's assignment of Tiresias to the state of God for Rose is but a "misunderstanding-as a superhuman gift" (Rose 88). In contrast to the intelligence of Oedipus, he finds Tiresias' blindness par excellent because "the power of the gods here is simply Teiresias... he makes more unscrupulous use of his divine gifts than Oedipus does of his royal power. But the man who sees the same things as the god must be something more than a man" (Lattimore 108). Lattimore generalizes insufficient intelligence of Oedipus to "efficacy of all human understanding" where Tiresias "takes on some of the most important aspects of divinity" (108). In similar vein, Hanna Geldrich-Leffman considers Tiresias' blindness as knowledge on a deeper, intuitive level.

Like Lattimore, Leffman also believes, "the gift of prophecy is given to them as to Tiresias by the gods as a form of recompense. Blind therefore become the real seers, the soothsayers" (672).Leffman's view of blindness as gift is based on his fatalistic concept. Likewise, for Jean-Paul Borel characters blindness is not a negative quality, but "a deeper insight and a deeper sensitivity and is therefore likened to the figure of Tiresias" (qtd. in Leffman 680). Conversely to these critics, Charilaos N. Michalopoulos defines blindness of Tiresias and Oedipus as justifiable punishment which "occurs as punishment for a sexual crime. For Oedipus it is patricide and incest; for Tiresias it is either the forbidden glimpse of a naked goddess" (233). Michalopoulos equates the blindness of both Tiresias and Oedipus as a return of their wrong doings.

Critical appraisals to Raymond Carver's Cathedral and Sophocles' Oedipus Rex do their best to unravel different theoretical issues. However, the critical eyes concentrated on the texts fall short to judge blindness as new body possibility. Provided with this point of departure, the study examines how blind protagonistswith par excellencecomprehend knowledge more than their normal counter characters and thus with their super cripple qualities challenge the imperatives of ableist ideals. The authors provide utmost consequences of blindness in their respective characters Robert and Tiresias. But the way these blind characters see things nobody else can see, makes the presumptions of their counter characters' on their blindness flipped. They question the "taken-for-granted sense of the normal doing of things" (Titchkosky 16). Moreover, these blind emancipate their counter characters from their ironical blindness, their inability to seeing the realities with normal eyes, leading them to acquisition of knowledge.

To approach the disable subjects in literature, Lennard J. Davis focuses on the significance of disability that can alter the common perception on disable subjects portrayed in literature. He asserts: "disabilities-studies' consciousness can alter the way we see ... main characters who are disabled. This normalcy must constantly be enforced 
in public venues (like the novel), must always be creating and bolstering its image by processing, comparing, constructing, deconstructing images of normalcy and the abnormal" (27). Davis considers literature as best venue to uncover the representation of alternative body possibilities against able-bodied ideology. In the similar tune, Nickianne Moody proposes "disability-informed criticism" as a methodology that "requires the researcher to focus on the fictional disabled subject, their interrelations within the narrative and the context of disability in the fictional world. From this vantage point ... meaning of disability to the culture . . . is produced and consumed ...” (32). For a research venture, Moody recognizes literary world and its representation as proper medium to explore the issues of disabilities. Rod Michalkoin the same tune observes literature asplace where readers can explore on how disability is culturally constructed program. He avers: "Fictional explorations of disability make it clear that disability is a socially constructed idea. Disability studies tend to focus on portrayals of social stereotypes when exploring the images of the disabled in literature" (43).

Michalko'savowal locates literary space as apt vantage point to endeavor the dynamics of resistance against ableist dogma and redefine the established definition of ability and disability.

\section{Dichotomy of Body Ideologies - Normality and Disability}

The terms 'blindness' and 'insight' designate the fundamental dichotomy of normal and disable body ideologies prevalent in cultural setting. Maren Linett puts her view on how concept of the termsstems from ableist culture's perception of human possessing knowledge or lacking of it:

Blindness is associated mostly with lack of knowledge and occasionally with uncanny knowledge, or insight. With its cultural encoding, blindness has been associated with lack of knowledge and insight. For the most part, blind people are thought to be excluded from knowledge, and anyone can be blind to the facts. (28)

The ocularcentric ableist culture assumes that the knowledge is received through the sight of physical eyes and associates blindness with lack of knowledge. Ved Mehta remarks: "the sighted go from one extreme to the other from assuming that the blind are virtually cut off from all perception to endowing them with extra sensory perception" (3). This attribution of extrasensory perception can also be explained by the ableist assumption that knowledge is synonymous to sight. Sighted people blame that if blind people possess knowledge they possess it by mysterious way. Disability like blindness is then socially constructed idea where "several denotative meanings of the word blind relate to the idea of lacking awareness or knowledge" (Bolt 268). The powerful ideology of ablebodiedness defines, interprets, and assigns the meaning of disability.

In Cathedral, Carver showcases the narrator as a person limited to the narrow cultural closet which restricts him from being able to see beyond the established definition of blindness. He learns that Robert, his wife's blind friend is visiting guest in their home. From the beginning he stereotypically interprets Robert's disability and derides him accordingly. While he thinks of and interacts with Robert, he relies on his preconceived notions of the blind. He locates himself "inside a normative ideology around the correct body situating bodily difference [of Robert] as mistake" (Stille 46). The narrator reveals: "his being blind bothered me. ... My idea of blindness came from the movies.... In the 
movies, the blind moved slowly and never laughed. ... Sometimes they were led by seeing-eye dogs" (Carver 359). In his perception, the narrator displays his stereotypical psyche, "cultural primacy of vision" (Leffman 673) against the blind. The narrator's perception is based on stereotypical treatment of ablebodied society against the disable people. He relies on the prejudices and treats Robert in a negative manner, "the dominant narratives of sight in the social construction" (Stille 48). The perception of his eyes is false, biased and limited within the sphere of socially defined normalcy. This is apparent while in his initial judgment of Robert. Despite his normal physical eyes, the narrator has false perception of Robert. Thus, irony resolves his perception. In fact, the narrator, who physically sees, is unable to see past the surface level.

The narrator defines Robert narrow-mindedly. His definition contours nonacceptance, social isolation and segregation of the disableas he mutters: "A blind man in my house was not something I looked forward to" (Carver 359). He worries that Robert is blind who does not possess quality of fun, and therefore no good to have around. Heposition to define "the blind ... [as] helpless and . . . dependent and the sighted must help the blind" (Kemp 79) is apparent in his action. That is why, the narrator "was not enthusiastic about his visit" (Carver 359). The narrator imposes the stereotype that disable people are helpless, weird and inferior. Narrator's comments on Robert typify the negative representation of blind people. In Fiona Kumari Campbell's words, stereotypical representations of disable peoplelike these are based on "the ideological foundation of the epistemologies and ontologies of ableism” (qtd. in Stanley 73). The ideological construction of body in ableist society follows the standards of fitness of body organs outside and inside.

Robert is blind; the only reason that makes the narrator feel unhappy with his arrival at his home. Narrator's reluctant expressions on Robert read, "it was beyond my understanding," "I started to say something . . . But I didn’t say anything,” "I didn’t know what to say," "how could I begin to describe it," "I wasn’t getting through to him”, "never read the expression” (Carver 362-70). The narrator in his position conceives Robert's disability not just as the physical issue. Rather hemanifests power relationship since "disability is a state of absolute difference rather than simply one more variation in human form ... the power relations between the subject positions of disabled and ablebodied" (Thomson 57). Narrator's preconceived judgment on Robert representsdominant social attitudes against the disables. To the condition of Robert, the narrator comments: "I felt sorry for the blind man" (Carver 362). Narrator's reaction to Robert's condition is of pity, and sympathy, a culturally constructed gap between disable and able-bodied. By showing sympathy to "pathetic" (362), Robert, narrator creates hierarchy of 'self' and 'other', powerful and powerless. Furthermore, he treats Robert's blindness from the point of view of socially inscribed identity as he defines Robert's eyes as "creepy" (364). The narrator exhibits stigmatization, "the value judgments of a dominant group" (Brown 148). With these, Carver treats disability as inconvenient life. His judgment of Robert suggests that all identities are socially constructed through the narratives about the body.

The narrator's prejudices against Robert persist on. However, throughout the narrative, his preconceived views of the blind are continuously challenged by Robert's actions. To his surprise, Robert succeeds to gather sensory experience as he is able to touch his wife’s, " face, her nose- even her neck!" (Carver 360). It makes easier for the narrator to judge Robert on the basis of his disability. The narrator sees Robert without 
cane and dark glasses against his preconception that "cane and . . . dark glasses were a must for the blind" (364). Robert furthermore continues to shock the narrator when he sees Robert smoking a cigarette and finding his food on his plate. The narratorhas the false perception that blind is unable to smoke because they cannot "see the smoke they exhale” (364) but Robert's was not the similar case. Gradually, narrator's perception towards Robert changes as he begins to watch him "with admiration" (365). Robert is blind, but that does not hinder him from smoking, drinking, watching TV and participating in the activities of the narrator and his wife. This makes narrator feel "glad for the company" (368) with him. Robert's character ultimately demonstrates the fact that prejudices made against the blind are subject of misrepresentations.

At the end of the story, Robert through mediated contour drawing regains his insight while he visualizes cathedral. His reconstruction of cathedral establishes the idea that insight through blindness is metacritical activity. Cathedral thus becomes the metaphor of insight akin to truth and wisdom. Robert's insight to knowledge and truth depicted as accessible to touching and feeling dismantle the cultural idea of insight relational to physical eyes. Moreover, Robert is able to dispensing him the knowledge and emancipate the narrator from his ignorance. After the drawing Robert asks the narrator, "I think you got it. Take a look" and the narrator replies, "it's really something" (Carver 372), a transformative epiphany. With the role reversal in the characters of Robert and the narrator, Carver interrogates the culturally encoded dichotomy of blindness and insight.

It is significant that most of the blind people acquire insights with auditory and touching capacity; the privileged modes of communication. In this sense, blindness is extraordinary locus of knowledge; it opens a new perspective to look at the world in new way. Rod Michalko states: "blindness is not ordinary. It provides everyone with the occasion to think about what is important and reminds everyone that a thoughtful life is more valuable than an ordinary one" (7). Like any other disability, in cultural space of its definition, blindness receives negative interpretation. Yet, in its in-depth examination, blindness possesses the abundance of vision and insight beyond the cultural definition of disability as depicted in the character of Tiresias.

Sophocles' Oedipus Rex dramatizes the ironic combination of blindness and insight in Tiresias and Oedipus. At the beginning of the play, the Chorus describes Tiresias as a prophet and praises the super ability of his blindness. When the city of Thebes badly suffers from a terrible plague, Chorus pleads the king to consult the wisdom of Tiresias. To the skill of Tiresias, Choragos, the leader of Chorus praises: “A lord clairvoyant to the lord Apollo, as we all know, is the skilled Tiresias . . in whom, alone of all men, truth was born" (Sophocles 813). His vision is like that of the gods as the chorus gives him equal status of Apollo. In this regard, Hanna Geldrich-Leffman vindicates: "the gift of prophecy is given to Tiresias by the gods as a form of recompense. Blind therefore become the real seers, the soothsayers" (672). Tiresias is unable to see the physical world but it has made him to see past it. Thus, he is provocative disable figure who transcends the dichotomy between disability and ablebodiedness. He fits into the category of what J. L. Langworthy asserts: "The blind are devious, exceptionally clever, having special talents, possessed of a magical quality, or having a special personality in compensation for their handicap" (qtd. in Kemp 79). 
Tiresias' possesses such a compensatory gift that he transcends the perception of physical reality and the spatial boundary of past, present and future.

In contrast, counter character Oedipus operates offensive cultural valuesagainst the disability. He judges Tiresias' blindness frompreconceived notion of normalcy. "You damned abracadabra" (Sophocles817), he insults Tiresias. Oedipus exhibits "the prejudiced attitudes of sighted persons who come in contact with the blind" (Kemp 15) in his treatment against Tiresias. But, Tiresias a man with defective eyes sees but Oedipus with his normal eyes does not see and here in lies the irony. Thus, his portrayal of contrastive characters in Tiresias and Oedipus is to contest "culturally agreed-upon designations of normality" (Mintz 159). With this, Sophocles confirms his character Tiresias as a super-cripple hero who outsmarts the illusive vision of Oedipus' physical eyes. Against the false depictions of blindness that it "inverts, perverts, or thwarts all human relationships" (Kleege 71), Sophocles represents blindness which leads the protagonist to insight. He dismantles the idea of blindness as frightening case and instead establishes it as perfect human condition.

Although devoid of vision, the blind people embody cognitive eyes that visualize insight and, thus, transcend the blind insight of normal physical eyes. With compensatory gift of insight, Tiresias' insight designates the"transcendent vision" (Barasch 133). In normative sense, he is unable to see but is able to dispense sight to others in the form of prophecy. Tiresias tells Oedipus about the future he must go with.However, showing no trust upon Tiresias, Oedipus' simply disregards Tiresias soothsaying. It is because he values upon his own physical eyes. Oedipus' character lacks foresight as he derides Tiresias for his physical blindness in the similar manner the narrator of "Cathedral" does to Robert. Oedipus exhibits the superiority of normalcy and underestimates the blindness of Tiresias as he disdains: "sightless ... old man. Collector of dirty pennies this old fraud. He is no more clairvoyant than I am" (Sophocles 815). Oedipus denial of Tiresisas' skill is based on what Rod Michalkonotes: "When blind people possess knowledge, sighted people assume they have come by it through uncanny means" (qtd. in Stille 46). Whenever he talks to Tiresias, he maintains his position of normalcy and exposes the hubris of kingly power. Tiresias is a figure who is entrapped within social boundaries. Lennard J. Davis holds: "the problem is not the person with disabilities; the problem is the way that normalcy is constructed to create the problem of the disabled person" (12). Davis examines that the problem of disability is created out of the hegemony of normalcy. In Judith Butler's definition, Oedipus uses 'inside' and 'outside' discourse of power while judging the disability of Tiresias. Because Tiresias is blind, Oedipus treats him on the basis of what Butler calls "exclusionary matrix" where "the subject is constituted through the force of exclusion and abjection" (3). Oedipus keeps himself inside at the same time outsides Tiresias to expose the power hierarchy between normalcy and disability, king and pauper.

Oedipus urges Tiresias to reveal the truth behind plague but he hesitates, "I shouldn't have come. . . let me go home" (Sophocles 814). Tiresias' hesitation is caused not only bythe kingly power of Oedipus but more by the fear blind (disable) people have. Why blind people fear, Alan Gowman clarifies: "Blindness creates formidable social and psychological problems for the individual. These problems are compounded by the fear" (qtd. in Kemp 13). Oedipus becomes suspicious of Tiresias's intention and shifts his focus to the physical aspects of vision. At this point, Oedipus exhibits hisstereotypical 
understanding of sight and blindness. In his anger against Tiresias he convicts: "What a wicked old man you are? . . . You sightless, witless, senseless, mad old man!" (Sophocles 814-15). He not only insults the disability of Tiresias but also otherizes him from the point of the stereotyping fixity of the culture, "the ideological construction of otherness" (Bhabha 37). Oedipus judges Tiresias with able-bodied gaze demonstrating the sociallyconstructed version of disability. There is an inherent assumption in Oedipus that knowledge acquisition requires the use of sight. In this regard, Ved Mehta observes: "the sighted go from one extreme to the other - from assuming that the blind are virtually cut off from all perception" (qtd. in Kemp 3). Oedipus judges Tiresias with dominant notion of knowledge based on the ontology of physical sight.

Tiresias cannot bear the insult made by Oedipus against him. In a rage he retorts:"You mock my blindness. But I say that you with your eyes, are blind. You do not even know the blind wrongs" (Sophocles 816). Tiresias' conviction foreshadows Oedipus' past and discovery of the truth. Henot only subverts the definition of insight and blindness but also proves the tendency of locating truth and knowledge on the illusive perception of physical eyes as wrong assertion. Oedipus with his normal eyes is blind because he is unable to recognize the truth. He is a sighted man but ignorant of reality. Insufficient intelligence of Oedipus in Steven Lattimore's words is "efficacy of all human understanding" (108). In contrast, Tiresias' despite his blindness holds the knowledge in his deeper, intuitive level. As the plot unfolds, Tiresiasdeclaration, “A blind man who has his eyes now, a penniless man, who is rich now. To the children with whom he lives now, he will be brother and father" (Sophocles 817) proves to be true. Nevertheless, Oedipus does not believe in Tiresias' saying since he is inclined to his own illusionary sense of knowledge.

As Oedipus gradually revisits the information of his past life, he becomes increasingly aware that he had murdered his father and married his mother. He laments: "Ah God! It was true. All the prophecies - now" (Sophocles 836). At this moment, Oedipus cannot negate the divine vision of Tiresias. After the truth is revealed, Oedipus blinds himself by broaching his eyes. By blinding himself Oedipus emancipates from the illusion of physical eyes and enters in the world of insight possible in the form of blindness. He makes the final remarks, "O light! May I look on you for the last time!" (836). He realizes that light/sight that does not help him to recognize the truth is worthless. The play ends with Oedipus' acquainting knowledge in the blindness. He addresses to himself, "The blind man! Yes even blind I know. Through my new darkness hide the comforter" (Sophocles 841). His realization convenes with what Tiresias had earlier described. Sophocles providing darkness to Oedipus, thus, symbolizes his acclaimed wisdom. He only knows the truth once he is blind. Sophocles brings Oedipus in the lineage of Tiresias in which blindness and wisdom are fused. In other words, Tiresias' blindness serves as a powerful metaphor that provides transformation of Oedipus from ignorance to knowledge.

\section{Conclusion}

To sum up, Carver and Sophocles portray their blind protagonists with supercripple body possibilityin order to challenge normative ideology around the correct body narrative. They exhibit super strengths in Robert and Tiresias toestablish the idea that disability is fundamental phenomena of cultural construction. In this sense, Oedipus Rex 
and Cathedral portray their protagonists with impairment as extraordinary heroes. Robert and Tiresias possess super ability to see the world more than the normal people do. Indeed, they carry over the myth that blind people have stronger sense unparalleled to normal human beings. Their insight is so powerful that it transgresses all the boundaries imposed to the blind. Therefore, in fictional world Robert and Tiresias are the able disabled or disabled heroes who overcome their disabilities. The super-ability of Robert and Tiresias is fictional, but their characters turn our view to similar sort of heroes in real world. They compel the readers to deconstruct culturally pre-designed definition of ability and disability.

\section{Works Cited}

Barasch, Moshe. Blindness: The History of a Mental Image in Western Thought. Routledge, 2013.

Bhabha, Homi K. "The Other Question: The Stereotype and Colonial Discourse." Screen, vol. 24, no. 6, 1983, pp. 18-36.

Bolt, David. "The Blindman in the Classic: Feminisms, Ocularcentrism and Charlotte Brontë's Jane Eyre." Textual Practice, vol. 22, no. 2, 2008, pp. 269-289.

Brown, Arthur. "Raymond Carver and Postmodern Humanism." Critique: Studies in Contemporary Fiction, vol. 31, no. 2, 1990, pp. 125-136.

Brown, Lerita. "Stigma: An Enigma Demystified." The Disability Studies Reader, edited by Lennard J. Davis, 4th ed., Taylor \& Francis, 2006, pp. 147-172.

Bruhn, Jørgen. "'This Beats Tapes, Doesn't It?’: Women, Cathedrals, and Other Medialities in Raymond Carver's "Cathedral.” The Intermediality of Narrative Literature, vol. 10.1057/97, 2016, pp. 61-82.

Bullock, Chris J. "From Castle to Cathedral: The Architecture of Masculinity in Raymond Carver's 'Cathedral'." The Journal of Men's Studies, vol. 2, no. 4, 1994, pp. 343-351.

Butler, Judith. Bodies That Matter: On the Discursive Limits of "Sex". Routledge, 2014.

Carver, Raymond. "Cathedral." Fiction: A Pocket Anthology. Edited by R S Gwynn, 4th ed., Penguin Academics, 2005, pp. 359-372.

Clark, Robert C. "Keeping the Reader in the House: American Minimalism, Literary Impressionism, and Raymond Carver's 'Cathedral'." Journal of Modern Literature, vol. 36, no. 1, 2012, pp. 104-118.

Davis, Lennard J. The Disability Studies Reader. 4th ed., Routledge, 2013

Geldrich, Leffman. "Vision and Blindness in Durrenmatt, Buero Vallejo and Lenz." MLN, vol. 97, no. 3, 1982, pp. 671-693.

Johnston, Taylor. "'Inside Anything': The Evacuation of Commodified Space in Raymond Carver’s 'Cathedral'." The Raymond Carver Review, vol. 5, no. 6, 2017, pp. 13-34.

Kemp, Nigel. "Social Psychological Aspects of Blindness: A Review." Current Psychological Reviews, vol. 1, no. 1, 1981, pp. 69-89.

Lattimore, Steven. "Oedipus and Tiresias." California Studies in Classical Antiquity, vol. 8, no. 1, 1975, pp. 105-111.

Linett, Maren. "Blindness and Intimacy in Early Twentieth-Century Literature." Mosaic: a Journal for the Interdisciplinary Study of Literature, vol. 46, no. 3, 2013, pp. 27-42. 
Michalko, Rod. "What’s Cool about Blindness?" Disability Studies Quarterly, vol. 30, no. 3/4, 2010, pp. 7-29.

Michalopoulos, Charilaos N. "Tiresias between Texts and Sex." EuGeStA, vol. 2, no. 1, 2012, pp. 221-239.

Mintz, Susannah B. "Invisible Disability: Georgina Kleege's Sight Unseen." NWSA Journal, vol. 14, no. 3, 2002, pp. 155-177.

Moody, Nickianne. "Methodological Agendas: Disability-Informed Criticism and the Incidental Representation of Autism in Popular Fiction." Popular Narrative Media, vol. 1, no. 1, 2008, pp. 25-41.

Newman-Stille, Derek. "Where Blindness is Not (?) a Disability: Alison Sinclair's Darkborn Trilogy." Mosaic: A Journal for the Interdisciplinary Study of Literature, vol. 46, no. 3, 2013, pp. 43-58.

Peterson, Polly R. "Psychological Distance in Raymond Carver's Cathdral." The Explicator, vol. 70, no. 3, 2012, pp. 167-169.

Prasain, Ramesh. "National Sovereignty and Foreign Intervention: Public Speaker Nepal 2 Winner." YouTube, Accretive Media, 11 Jan. 2021, https://www.youtube.com/watch?v=KuxoBLUdPj0. Accessed 7 Feb. 2021.

Rose, Martha L. The Staff of Oedipus: Transforming Disability in Ancient Greece. U of Michigan P, 2003.

Sophocles. “Oedipus Rex.” Elements of Literature: Essay, Fiction, Poetry, Drama, Film, edited by Robert Scholes et al., translated by Michael Silverman and DudelyFitts, 4th ed., Oxford UP, 1991, pp. 804-46.

Stanley, Sandra K. "Maggie in Toni Morrison's "Recitatif": The Africanist Presence and Disability Studies." MELUS: Multi-Ethnic Literature of the U.S, vol. 36, no. 2, 2011, pp. 71-88.

Thomson, Rosemarie G. Extraordinary Bodies: Figuring Physical Disability in American Culture and Literature. Columbia UP, 2017.

Titchkosky, Tanya. Disability, Self, and Society. U of Toronto P, 2003. 